\title{
Listeria Infection in Pregnancy: A Review of Literature
}

\author{
Carmen De Luca, Laura Donati, Luisa D’Oria, Angelo Licameli, Marcella Pellegrino and \\ Marco De Santis ${ }^{*}$
}

\author{
Telefono Rosso, Teratology Information Service Department of Obstetrics and Gynaecology, Catholic University of \\ Sacred Heart, Policlinico Agostino Gemelli, Rome, Italy
}

\begin{abstract}
Listeria monocytogenes, a Gram-positive bacterium, is responsible for human listeriosis. Infection with Listeria has been associated with the consumption of contaminated and/or inadequately cooked food, particularly dairy products, leafy vegetables, fish, and meat. The main clinical manifestations include diarrhea, nausea and vomiting, which are usually followed by fever and flu-like symptoms.

Listeriosis affects pregnant women in about one in seven (14\%) cases. They are approximately 10 times more likely to catch the disease than the general population. Although Listeria infection during pregnancy is usually uncomplicated for the mother, fetal and neonatal infection can be severe and fatal. Animal studies have shown a dose-response relationship between L. monocytogenes bacterial load and adverse pregnancy outcome, mainly pregnancy loss. Fetal and neonatal infection occurs through the transplacental passage of the bacterium or through exposure in the perinatal period. In pregnant women Listeria infection was associated with fetal loss, preterm birth, neonatal infection or neonatal death. Blood culture is the principal diagnostic tool and the antibiotic of choice for the treatment of listeriosis is penicillin, with high doses injected intravenously for at least 14 days. In case of suspected or confirmed maternal listeriosis, a program of fetal surveillance should be implemented. Common fetal ultrasound findings in listeria infection include non-immune hydrops, intracranial calcifications, and intrauterine fetal demise. Strategies for the prevention of listeriosis, including avoiding unpasteurized dairy products, uncooked food and leftover food, have significantly decreased the number of cases of infection. Prevention in pregnant women can be achieved by sticking to prophylactic measures and strict diet recommendations.
\end{abstract}

Keywords: Listeria, listeriosis, neonatal sepsis, pregnancy.

\section{INTRODUCTION}

Listeriosis is predominantly a food borne disease which mostly affects people with a compromised immune system, older people, pregnant women and newborns. Maternal infection from Listeria monocitogenes can significantly influence fetal and neonatal outcome, since it can cause early and late fetal loss, preterm delivery and neonatal sepsis. We have performed a mini review of literature on this topic. Potential articles were identified by searching PubMed, ISI Web of Science, and SCOPUS databases. We searched for "maternal listeriosis", "fetal listeriosis", "listeria infection in pregnancy", "listeria infection in newborns", "early onset listeriosis" and "late onset listeriosis". All epidemiological studies, as well as case-control studies, case-cohort studies, case reports, and case series published until December 2014 were eligible for inclusion in the review.

\section{EPIDEMIOLOGY AND PATHOGENESIS}

There are multiple species of Listeria including $L$. monocytogenes, L. fleischmannii, L. welshimeri, L. innocua,

*Address correspondence to this author at the Telefono Rosso, Teratology Information Service Department of Obstetrics and Gynaecology, Catholic University of Sacred Heart, Policlinico Agostino Gemelli, Rome, Italy; Tel: +39 0630156525; Fax: +39 0630156572;

E-mail: marcodesantis@rm.unicatt.it
L. marthii L. ivanovii, L. seeligeri, L. grayi and L. murrayi [1-3]. But among these different species only $L$. monocytogenes has been found to be implicated in human disease. It is a ubiquitous aerobic and facultative anaerobic, gram-positive and motile bacillus. L. monocytogenes includes 16 servovars, but only type $4 \mathrm{~b}$ seems to be responsible for food borne listeriosis [3]. The bacillus grows between $30-37^{\circ} \mathrm{C}$ and has the ability to multiply at commonly set refrigerator temperatures $\left(4-10{ }^{\circ} \mathrm{C}\right)$. This capacity is responsible for its transmission through the consumption of food products $[4,5]$. The bacillus can be eliminated by pasteurization. L. monocytogenes tolerates both high and low temperatures as well as high salt concentrations, although it may be eliminated by using some disinfecting agents. This capacity to adapt to different conditions allows it to be present in different locations, including water, soil, dust, liquid waste, animal feeds and animal waste [6]. Animals may be infected by spoiled silage [7-11]. Listeriosis is commonly acquired through the ingestion of contaminated food [12], including dairy products derived from unpasteurized milk (especially soft cheese) [13] and ready-to-eat meat dishes, such as meat paté [14], pork tongue in jelly [15], turkey delicatessen meat [16], hot dogs [17]. Colonization of the gastrointestinal (GI) tract by L. monocytogenes may be transitory and can be detected in $5-15 \%$ of normal adult stool samples. Other colonization sites are represented by the pharynx, vagina and cervix [3-5, 18]. The Center for Disease Control and Prevention (CDC) 
estimates that in 2013, the incidence of listeriosis in the United States was 0.26 cases per 100,000 individuals [19] and compared to $1996-1998$, it had declined by about $42 \%$ by 2012 [20]. In 2012, the incidence of reported Listeria infections in Europe was 0.41 per 100,000 people, with a statistically increasing trend in the period 2008-2012, though only slowly increasing [21]. Possible explanations of these differences can be found in different food habits, such as the decreased concentration of salt in prepared foods and the tendency to purchase food from small local food stores and convenience stores in Europe [22, 23].

According to CDC, Listeriosis affects pregnant women in about one in seven (14\%) cases; they are approximately 10 times more likely than the general population to catch the disease [24]. In particular, pregnant Hispanic women represent an ethnicity at risk, probably because of certain food at risk of contamination $[6,25]$. In fact, they are about 24 times more predisposed to being infected than the general population [24].

Other categories at risk are represented by adults over 65 years and people with a weakened immune system [26]. Since the immune response to Listeria infection is mostly cell mediated, people with compromised cell-mediated immunity, such as patients with HIV-infection associated immunosuppression or patients who underwent organ transplantation and pregnant women are more likely to catch listeriosis $[27,28]$.

The oral bacterial load seems to be $10^{4}-10^{6}$ organisms per each gram of ingested food [29], while the incubation period is approximately between 2 and 6 weeks $[3,4]$. Some drugs such as $\mathrm{H} 2$ blockers, antacids and laxatives have been shown to promote the disease $[5,30]$, as well as iron and hemochromatosis [5]. After penetrating the mucosal barrier of the GI tract, the bacterium spreads hematogenously to the other organs, preferring the Central Nervous System (CNS) and the placenta [3].

\section{CLINICAL MANIFESTATIONS}

Maternal infection may be asymptomatic in $29 \%$ of cases [31]. The most frequent clinical manifestations include diarrhea, nausea and vomiting, which are usually followed by fever and flu-like symptoms such as headache, myalgia, and backache [31-34]. Sepsis can occur in patients with a deficient immune system. Symptoms of sepsis include fever, GI symptoms and malaise and it can lead to adult respiratory distress syndrome (ARDS), disseminated intravascular coagulation (DIC), and multi-organ system failure [2-5]. CNS disease also occurs in immunocompromised patients and it is usually represented by meningitis. If the brainstem is involved, literal rhombencephalitis occurs. It is rare and represents a particularly severe form of infection, with high mortality and frequent sequelae [6]. Clinical manifestations include 3-5 days of fever, nausea, vomiting and headache and can lead to coma in the immunosuppressed population or in patients over 65 years [3, 30]. Subsequent clinical manifestations include nuchal rigidity (in 50\% of the cases), hemiparesis, cranial nerve deficits, cerebellar signs, unconsciousness and sensory loss $[4,5]$. CNS infection can also lead to brain abscesses in approximately $10 \%$ of cases $[4,5]$. Listerial endocarditis usually affects patients with a damaged native cardiac valve or prosthetic valve. It has a mortality rate of $50 \%$ and infection involves preferentially left-sided valves, often becoming a source of systemic emboli [3, 4]. Other clinical manifestations of human listeriosis include pericarditis, pleuritis, osteomyelitis, hepatitis, cholecystitis, splenic abscess, peritonitis, endophthalmitis and conjunctivitis. They may be caused by septic emboli of listerial endocarditis [2, 3].

\section{PREGNANCY COMPLICATIONS}

Pregnant women represent a population at risk for listeriosis since cell-mediated immunity is moderately depressed during pregnancy [3]. Listeriosis may appear at all stages of gestation but is most common in the last trimester. Maternal infection may be asymptomatic or may present flulike symptoms such as fever, headache, myalgia and backache, commonly preceded by GI symptoms [31-33].

Although often uncomplicated, fetal and neonatal infections may lead to severe consequences. Animal studies on guinea pigs, rhesus monkeys, and mice showed a doseresponse relationship between increasing bacterial load and adverse pregnancy outcome, mainly pregnancy loss [35-37]. Bacteremia causes transplacental infection, which may lead to spontaneous abortion, fetal death, premature rupture of membranes, premature labor, chorioamnionitis, or neonatal infection [3]. Intrauterine infection presents with common symptoms of Listeria infection accompanied by bloody vaginal discharge $[38,39]$. The placenta represents a site of choice for the bacterium: after the infection, it becomes a reservoir for re-infection. Animal experiments on a pregnant guinea pig showed that the infected placenta becomes a source of infection for other organs until it is expelled According to the authors, "spontaneous abortion and prematurity can be regarded as survival mechanisms for the mother" [40]. Robbins et al. analyzed cultures of first trimester human placental explants demonstrating that the syncytiotrophoblast was highly resistant to $L$. monocytogenes and the extravillous cytotrophoblasts represents "the main portal of entry into the placenta" [41]. In case of human infections, histological examination of the placenta may show signs of chorioamnionitis, vasculitis, funisitis, and acute villitis with abscesses [42]. The abscesses are usually multiple, well circumscribed, gray and solid. Gram and Silver impregnation stains can be used to identify the organism [3]. Fetal infection usually occurs through the transplancental passage of the microorganism. Other possible routes of transmission are represented by ascending infection through intact membranes or during vaginal delivery. Moreover nosocomial infection may occur after birth [3]. The infection affects the fetus in more than $90 \%$ of cases of maternal listeriosis; perinatal mortality includes fetal loss or neonatal death with a frequency of approximately $29 \%$ [3, 43]. In a case series of 722 cases of Listeria infection during pregnancy the spontaneous abortion rate was $10-20 \%$, intrauterine fetal death occurred in approximately $11 \%$ of cases and fetal distress rate was $34 \%$ [31]. Infection that occurs before 20 weeks of gestation usually causes fetal death, while after 20 weeks it results in preterm labor in $50 \%$ of cases. The amniotic fluid is meconium stained in $75 \%$ of cases of maternal infection, particularly at early gestation, probably due to the ingestion 
of infected fluid, which causes fetal enteritis [31, 44]. In a case series of women with positive cervical cultures for $L$. monocitogenes, these patients seemed to have a higher risk of recurrent abortion [45], although other studies failed to confirm these findings [18, 46-48]. Discordant infection can occur in twin pregnancy $[49,50]$ : the infected twin is commonly in the presenting position and this can be related to the ascending route of infection from the vagina [51]. In case of suspected or confirmed maternal listeriosis, a program of fetal surveillance should be implemented, including periodic cardiotocography and ultrasound examinations according to gestational age. The most frequently described antenatal symptoms are reduced fetal movements, an abnormal fetal heart rate trace, non-immune hydrops, intracranial calcifications and intrauterine fetal demise [52]. A case report also found the fetal ultrasound findings to include mild ascites, dilated gallbladder, and echogenic and dilated loops of the small bowel [53]. In case of suspected fetal listeriosis, amniotic fluid and cervical cultures may be useful $[53,54]$.

\section{NEONATAL INFECTION}

The incidence of neonatal listeriosis is approximately 8.6 every 100,000 live births $[6,55]$ and may be caused by ascending infection, transplacental passage of the organism or by inhalation of amniotic fluid [56, 57]. Moreover, nosocomial cross-infection has been reported [58, 59]. Clinical manifestations of neonatal listeriosis are similar to those of group B streptococcal infection and mortality rate is estimated to be between 20 and $60 \%$ [14, 31, 60, 61]. Neonatal infection occurs in $68 \%$ of the cases of maternal infection; a complete recovery may follow in approximately $68 \%$ of these cases, while long term sequelae can be observed in $12.7 \%$ of cases [31]. There are two forms of neonatal disease: early-onset disease (EOD) and late-onset disease (LOD). EOD occurs within one week from delivery but usually symptoms appear within 2 days after birth [62]. It is probably caused by intrauterine infection and associated with chorioamnionitis and preterm delivery. Septicemia is the most common clinical manifestation (81-88\%), but meningitis $(24 \%)$ and respiratory distress or pneumonia $(38 \%)$ can occur $[6,44,63]$. A particular form of EOD is granulomatosis infantiseptica, which is characterized by abscesses and granulomas on the skin and in the visceral organs [3, 64]. LOD is usually diagnosed between five days and two or more weeks post-partum, commonly in neonates born at term. Transmission probably occurs during the passage through the birth canal or through nosocomial infection [5, 6, 30]. Septicemia (17-95\%) and meningitis $(67-93 \%)$ are the most common clinical manifestations [65, $66]$.

\section{DIAGNOSIS AND MANAGEMENT OF MATERNAL LISTERIOSIS}

Maternal listeriosis may be difficult to diagnose, since clinical manifestations are not specific. Listeriosis may be suspected in pregnancy in case of fever or gastroenteritis where routine cultures turn out to be negative. Laboratory tests may show a leucocytosis, rather than a monocytosis. The isolation of the organism from a sterile site such as blood, spinal fluid, amniotic fluid or placenta [31, 33] allows to confirm the diagnosis. L. monocytogenes usually grows in culture within 24-36 hours; it can be revealed with Gram stain and it appears on microscopy in characteristic "tumbling" motion [6]. A negative culture does not rule out infection in the presence of strong clinical suspicion. Gram positive bacteria can be observed in the amniotic fluid, which is usually meconium stained [67]. Serological tests are usually not recommended by CDC [68]. Magnetic resonance imaging (MRI) can reveal CNS infection [3]. In 2014 the American College of Obstetricians and Gynecologists (ACOG) published a Committee Opinion providing a series of recommendations for confirmed or suspected cases of Listeria infection in pregnant women [32]. On the basis of these recommendations, no diagnostic exam or medical therapy is recommended for an asymptomatic patient who has consumed a product suspected to be contaminated by Listeria. Therefore, these pregnant women should be advised to inform their doctor of the onset of typical symptoms within 2 months. Fetal surveillance should be conducted as usual. In case of a pregnant woman with a presumptive exposure to Listeria and who has flu-like or GI symptoms but has no fever, an expectant management may be conducted or blood culture may be performed. In case of positive blood culture for $L$. monocitogenes, standard antimicrobial treatment for listeriosis would be advisable and initiating a program of fetal surveillance should be considered. In a symptomatic patient with a fever above $38.1^{\circ} \mathrm{C}\left(100.6^{\circ} \mathrm{F}\right)$, a blood culture should be performed and antibiotic treatment should be simultaneously started. Moreover, placental cultures are advisable after delivery [32]. ACOG recommend high-doses of intravenous ampicillin for the treatment of listeriosis, with at least 6 g/day, for nonallergic patients. Ampicillin therapy should be administered for at least 14 days [32, 69]. Gentamicin has a synergic action with ampicillin [70] and may be added to the treatment regimen, but its use is not universally recommended due to its toxic effects [32]. Trimethoprim with sulfamethoxazole is recommended in patients allergic to penicillin [69]. Since the CDC considers listeriosis a notifiable disease, health care providers should report the case of a confirmed listerial infection to their local public health departments. A program of fetal surveillance (including ultrasound examinations and cardiotocography on the base of gestational age) should be started in these categories of patients, although no precise recommendations are stated for such testing [32].

\section{PREVENTION OF MATERNAL LISTERIOSIS}

From the institutional point of view, listeriosis is part of the group of diseases for which surveillance networks on food safety have been established both in the US and Europe and it has been listed for mandatory notification in many countries [71]. These networks, aimed at detecting outbreaks and determining the cause, allow to take the necessary measures to prevent the diffusion of the disease. No vaccine for Listeria is currently available [6]. The general recommendations for the prevention of listeria infection include those suggested for the prevention of other food borne infections. CDC has issued general recommendations on how to prevent Listeria infection in common population 
Table 1. Centers for Disease Control and Prevention (CDC) recommendations to prevent Listeria infections.

\begin{tabular}{|c|}
\hline $\begin{array}{l}\text { General Recommendations } \\
\text { - } \\
\text { - } \\
\text { Dinse fruits and vegetables under running tap water before eating, cutting, or cooking } \\
\text { - } \quad \text { Separate uncooked from cooked foods, and ready-to-eat foods. } \\
\text { - } \quad \text { The refrigerator should be } 40^{\circ} \mathrm{F} \text { or lower and the freezer } 0^{\circ} \mathrm{F} \text { or lower. } \\
\text { - } \quad \text { Clean up all spills in your refrigerator right away } \\
\text { - } \quad \text { Thean the inside walls and shelves of your refrigerator with hot water and liquid soap. } \\
\text { - } \quad \text { Use precooked or ready-to-eat food as soon as you can. } \\
\text { - } \quad \text { Divide leftovers into shallow containers to promote rapid, even cooling. Cover and use leftovers within } 3 \text { to } 4 \text { days. } \\
\text { Do not drink raw (unpasteurized) milk, and do not eat foods that have unpasteurized milk in them } \\
\text { - } \quad \text { Do not eat hot dogs, luncheon meats, cold cuts, other deli meats or fermented or dry sausages unless they are heated to an internal temperature of } \\
165^{\circ} \mathrm{F} \text { or until steaming hot just before serving. } \\
\text { Avoid getting fluid from hot dog and lunch meat packages on other foods, utensils, and food preparation surfaces, and wash hands after handling } \\
\text { hot dogs, luncheon meats, and deli meats. } \\
\text { Do not eat refrigerated pâté or meat spreads from a deli or meat counter or from the refrigerated section of a store. Refrigerate after opening. } \\
\text { Do not eat soft cheese unless it is labeled as made with pasteurized milk. } \\
\text { Do not eat refrigerated smoked seafood, unless it is contained in a cooked dish }\end{array}$ \\
\hline
\end{tabular}

Modified from: Centers for Disease Control and Prevention. Listeria (listeriosis). Prevention. Available at: http://www.cdc.gov/listeria/prevention.html. Retrieved January 13 2015.

and some further recommendations for high risk subjects, including pregnant women [72]. These recommendations are listed in Table $\mathbf{1}$ and include general food safety, hygiene, high-risk foods to avoid during pregnancy, proper food preparation and storage. They should be discussed at the first prenatal visit.

\section{CONCLUSION}

Listeriosis is a food borne infection caused by the consumption of contaminated food and L. monocytogenes represents the etiologic agent. The most frequently involved foods include ready-to-eat preparations or products derived from unpasteurized milk. Pregnant women represent a population at risk for listeriosis. Although maternal infection is often asymptomatic or paucisymptomatic, the consequences for the baby may be very severe. From the first prenatal visit pregnant women should be taught to avoid high risk foods and to follow routine hygienic measures. All febrile episodes occurring during pregnancy should not be underestimated and need to be investigated. Obstetricians and family doctor should be familiar with the management of Listeria infection, since in case of maternal infection a prompt diagnosis and an adequate treatment are necessary to prevent possible maternal, fetal and neonatal consequences.

\section{CONFLICT OF INTEREST}

The authors confirm that this article content has no conflict of interest.

\section{ACKNOWLEDGEMENTS}

Declared none.

\section{REFERENCES}

[1] Baron EJ, Peterson LR, Finegold SM. Bailey and scotts diagnostic microbiology. $9^{\text {th }}$ ed. St Louis: Mosby, 1994: pp. 458-60.

[2] Rocourt J, Bille J. Foodborne listeriosis. World Health Stat Quarterly 1997; 50: 67-73.

[3] DiMaio H. Listeria infection in women. Primary care update for Ob/Gyns 2000; 7(1): 40-45.

[4] Fauci AS, Braunwald E, Isselbacher KJ, et al. Harrisons principles of internal medicine. New York: McGraw-Hill, 1998: 899-901.

[5] Lorber B. Listeriosis. Clin Infect Dis 1997; 24: 1-11.

[6] Lamont RF, Sobel J, Mazaki-Tovi S, et al. Listeriosis in human pregnancy: a systematic review. J Perinat Med 2011; 39(3): 22736.

[7] Al-Ghazali MR, Al-Azawi SK. Detection and enumeration of Listeria monocytogenes in a sewage treatment plant in Iraq. J Appl Bacteriol 1986; 60: 251-4.

[8] Fenlon DR. Rapid quantitative assessment of the distribution of Listeria in silage implicated in a suspected outbreak of listeriosis in calves. Vet Rec 1986; 118: 240-2.

[9] Kampelmacher EH, van Noorle Jansen LM. Listeriosis in humans and animals in the Netherlands (1958-1977). Zentralbl Bakteriol A 1980; 246: 211-27.

[10] Watkins J, Sleath KP. Isolation and enumeration of Listeria monocytogenes from Sewage, Sewage Sludge and River Water. J Appl Bacteriol 1981; 50: 1-9.

[11] Welshimer HJ, Donker-Voet J. Listeria monocytogenes in nature. Appl Microbiol 1971; 21: 516-9.

[12] Ross DS, Jones JL, Lynch MF. Toxoplasmosis, cytomegalovirus, listeriosis, and preconception care. Matern Child Health J 2006; 10(5 Suppl): S187-91.

[13] Centers for Disease Control and Prevention. Outbreak of listeriosis associatred with homemade Mexocan style cheese-Update. North Carolina, October 2000-January 2001. Morb Mortel Wkly Rep 2001; 50(26): 560-2.

[14] McLauchlin J, Hall SM, Velani SK, Gilber RJ. Human Listeriosis and pat'e: A possible association. BMJ 1991; 303(6805): 773-5.

[15] Jacquet C, Catimel B, Brosch R, et al. Investigations related tothe epidemic strain involved in the French listeriosis outbreak in 1992 Appl Environ Microbiol 1995; 61(6): 2242-6.

[16] Gottlieb SL, Newbern EC, Griffin PM, et al. Multistate outbreak of listeriosis linked to turkey deli meat and subsequent changes in US regulatory policy. Clin Infect Dis 2006; 42(1): 29-36. 
[17] Mead PS, Dunne EF, Graves L, et al. Nationwide outbreak of listeriosis due to contaminated meat. Epidemiol Infect 2005; 1: 1-8.

[18] Manganiello PD, Yearke RR. A 10-year prospective study of women with a history of recurrent fetal losses fails to identify Listeria Monocytogenes in the genital tract. Fertil Steril 1991; 56: 781-2.

[19] Centers for Disease Control and Prevention. Incidence and Trends of Infection with Pathogens Transmitted Commonly Through Food - Foodborne Diseases Active Surveillance Network, 10 U.S. Sites, 2006-2013. Morb Mortal Wkly Rep 2014; 63(15): 328-332.

[20] Centers for Disease Control and Prevention. Foodborne Diseases Active Surveillance Network (FoodNet): FoodNet Surveillance Report for 2012 (Final Report) Atlanta, Georgia: U.S. Department of Health and Human Services, CDC 2014

[21] European Food Safety Authority, European Centre for Disease Prevention and Control. The European Union Summary Report on Trends and Sources of Zoonoses, Zoonotic Agents and Food-borne Outbreaks in 2012. EFSA J 2014; 12(2): 3547.

[22] Allerberger F, Wagner M. Listeriosis: a resurgent foodborne infection. Clin Microbiol Infect 2010; 16: 16.

[23] Gillespie IA, Mook P, Little CL, et al. Human listeriosis in England, 2001-2007: association with neighbourhood deprivation. Euro Surveill 2010; $15: 7$

[24] Centers for Disease Control and Prevention. Listeria. Risk. Available from: http: //www.cdc.gov/listeria/risk.html

[25] Voetsch AC, Angulo FJ, Jones TF, et al. Reduction in the incidence of invasive listeriosis in foodborne diseases active surveillance network sites, 1996-2003. Clin Infect Dis 2007; 44: $513-20$.

[26] Centers for Disease Control and Prevention. Vital signs: listeria illnesses, deaths, and outbreaks - United States, 2009-2011. Morb Mortel Wkly Rep 2013; 62(22): 448-52.

[27] Morse SA, Brooks GF, Carroll KC, et al. Aerobic nonsporeforming gram-positive bacilli: Corynebacterium, Listeria, Erysipelothrix, Actinomycetes, \& related pathogens. In: Brooks GF, Carroll KC, Butel JS, et al., Eds. Jawetz, Melnick, \& Adelberg's Medical Microbiology. 25 ${ }^{\text {th }}$ ed. New York, NY: McGraw-Hill 2010

[28] Mardis BA, Conley CS, Jeffrey A. Kyle JA. Listeriosis: An overview. BCPS Disclosures US Pharmacist 2012; 37(8): 38-41.

[29] (a) Ho JL, Shands KN, Friedland G, Eckind P, Fraser DW. An outbreak of type $4 \mathrm{~b}$ Listeria monocytogenes infection involving patients from eight Boston hospitals. Arch Intern Med 1986; 146: 520-4. (b) Schlech WF III. Listeria gastroenteritis - old syndrome, new pathogen. N Engl J Med 1997; 336: 130-2.

[30] Goulet V, Marchetti P. Listeriosis in 225 non-pregnant patients in 1992: clinical aspects and outcome in relation to predisposing conditions Scand J Infect Dis 1996; 28: 367-74.

[31] Mylonakis E, Paliou M, Hohmann EL, Calderwood SB, Wing EJ. Listeriosis during pregnancy: a case series and review of 222 cases. Medicine (Baltimore) 2002; 81: 260-9.

[32] Committee on Obstetric Practice, American College of Obstetricians and Gynecologists. Committee Opinion No. 614: Management of pregnant women with presumptive exposure to Listeria monocytogenes. Obstet Gynecol 2014; 124(6): 1241-4.

[33] Jackson KA, Iwamoto M, Swerdlow D. Pregnancy-associated listeriosis. Epidemiol Infect 2010; 138: 1503-9.

[34] Benshushan A, Tsafrir A, Arbel R, Rahav G, Ariel I, Rojansky N. Listeria infection during pregnancy: a 10 year experience. Isr Med Assoc J 2002; 4: 776-80.

[35] Williams D, Irvin EA, Chmielewski RA, et al. Dose response, infectivity, and stillbirths in pregnant guinea pigs inoculation with Listeria moncytogenes. Birth Defects Res A Clin Mol Teratol 2006; 76(5): 381 .

[36] Smith MA, Anderson GA, McClure HM, et al. Dose response of Listeria monocytogenes-induced stillbirths in pregnant nonhuman primate model. Birth Defects Res Part A Clin Mol Teratol 2003; 67(5): 328.

[37] Irvin EA, Williams D, Voss KA, Smith MA. Immunological and pathological effects of Listeria monocytogenes infection in pregnant guinea pigs. Birth Defects Res A Clin Mol Teratol 2006; 76(5): 317 .

[38] MacGowan AP, Cartlidge PHT, MacLeod F, McLaughlin J. Maternal listeriosis in pregnancy without fetal or neonatal infection. J Infect 1991; 22: 53-7.
[39] Kalstone C. Successful antepartum treatment of listeriosis. Am J Obstet Gynecol 1991; 164: 57-8.

[40] Bakardjiev AI, Theriot JA, Portnoy DA. Listeria monocytogenes traffics from maternal organs to the placenta and back. PLoS Pathog 2006; 2: e66.

[41] Robbins JR, Skrzypczynska KM, Zeldovich VB, Kapidzic M, Bakardjiev AI. Placental syncytiotrophoblast constitutes a major barrier to vertical transmission of Listeria monocytogenes. PLoS Pathog 2010; 6(1): e1000732.

[42] Cheung VY, Sirkin WL. Listeriosis complicating pregnancy. CMAJ 2009; 181(11): 821-2.

[43] Silk BJ, Date KA, Jackson KA, et al. Invasive listeriosis in the Foodborne Diseases Active Surveillance Network (FoodNet), 2004-2009: further targeted prevention needed for higher-risk groups. Clin Infect Dis 2012; 54(suppl 5): S396-404.

[44] McLauchlin J. Human listeriosis in Britain, 1967-85, a summary of 722 cases. Listeriosis during pregnancy and in the newborn. Epidemiol Infect 1990; 104: 181-9.

[45] Rappaport F, Rabinovitz M, Toaff R, Krochik N. Genital listeriosis as a cause of repeated abortion. Lancet 1960; i: 1273-5.

[46] Macnaughton MC. Listeria monocytogenes in abortion. Lancet 1962; $2: 484$

[47] Lawler FC, Wood WS, King S, Metzger WI. Listeria monocytogenes as a cause of fetal loss. Am J Obstet Gynecol 1964; 89: $915-23$

[48] Ansbacher R, Borchardt KA, Hannegan MW, Boyson WA. Clinical investigation of Listeria monocytogenes as a possible cause of human fetal wastage. Am J Obstet Gynecol 1966; 94: 386-90.

[49] Forsnes EV, Heaton JO, Bowen E. Intrauterine Listeria infection of the nonpresenting twin. Obstet Gynecol 1998; 92: 715.

[50] Al-Tawfiq JA. Listeria monocytogenes bacteremia in a twin pregnancy with differential outcome: fetus papyraceus and a fullterm delivery. J Microbiol Immunol Infect 2008; 41(5): 433-6.

[51] Mascola L, Ewert DP, Eller A. Listeriosis: a previously unreported medical complication in women with multiple gestations. Am J Obstet Gynecol 1994; 170: 1328-32.

[52] Bailao, LA, Osborne NG, Rizzi MC, et al. Ultrasound markers of fetal infection, Part 2: Baterial, parasitic, and fungal infections. Ultrasound Q 2006; 22(2): 137-51.

[53] Hasbun J, Sepulveda-Martinez A, Haye MT, Astudillo J, ParraCordero M. Chorioamnionitis caused by Listeria monocytogenes: a case report of ultrasound features of fetal infection. Fetal Diagn Ther 2013; 33(4): 268-71.

[54] Benhaim Y, Aucouturier JS, Hillion Y, et al. The role of amniocentesis in the management of chorioamnionitis with Listeria monocytogene. J Gynecol Obstet Biol Reprod 2003; 32(1): 39-42.

[55] Centers for Disease Control and Prevention. Preliminary FoodNet data on the incidence of infection with pathogens transmitted commonly through food - 10 states, 2007. Morb Mortal Wkly Rep 2008; 57: 366-70.

[56] Becroft DM, Farmer K, Seddon RJ, et al. Epidemic listeriosis in the newborn. Br Med J 1971; 3: 747-51.

[57] Posfay-Barbe KM, Wald ER. Listeriosis. Pediatr Rev 2004; 25 : $151-9$.

[58] Quarles JM Jr, Pittman B. Unsuccessful attempt to detect Listeria monocytogenes in healthy pregnant women. J Bacteriol 1966; 91: 2112-3.

[59] Schuchat A, Lizano C, Broome CV, Swaminathan B, Kim C, Winn $\mathrm{K}$. Outbreak of neonatal listeriosis associated with mineral oil. Pediatr Infect Dis J 1991; 10: 183-9.

[60] Albritton WL, Cochi SL, Feeley JC. Overview of neonatal listeriosis. Clin Invest Med 1984; 7: 311-4.

[61] Schwarze R, Bauermeister CD, Ortel S, Wichmann G. Perinatal listeriosis in Dresden 1981-1986: clinical and microbiologicalfindings in 18 cases. Infection 1989; 17: 131-8.

[62] Relier JP. Perinatal and neonatal infections: listeriosis. J Antimicrob Chemother 1979; 5(Suppl A): 51-7.

[63] Linnan MJ, Mascola L, Lou XD, et al. Epidemic listeriosis associated with Mexicanstyle cheese. N Engl J Med 1988; 319: 823-8.

[64] Lallemand A, Gaillard D, Paradis P, Chippaux C. Fetal listeriosis during the second trimester of gestation. Pediatr Pathol 1992; 12: 665-71.

[65] Posfay-Barbe KM, Wald ER. Listeriosis. Pediatr Rev 2004; 25 : $151-9$. 
[66] Skidmore AG. Listeriosis at Vancouver General Hospital 1965-79. Can Med Assoc J 1981; 125: 1217-21.

[67] Mazor M, Froimovich M, Lazer S, Maymon E, Glezerman M. Listeria monocytogenes. The role of transabdominal amniocentesis in febrile patients with preterm labor. Arch Gynecol Obstet 1992; 252: 109-12.

[68] Centers for Disease Control and Prevention. Listeria. Diagnosis. Available from: http: //www.cdc.gov/listeria/diagnosis.html
[69] Janakiraman V. Listeriosis in pregnancy: diagnosis, treatment, and prevention. Rev Obstet Gynecol 2008; 1: 179-85.

[70] Temple ME, Nahata MC. Treatment of listeriosis. Ann Pharmacother 2000; 34: 656-61.

[71] Centers for Disease Control and Prevention. Listeria. Surveillance. Available from: http: //www.cdc.gov/listeria/surveillance.html

[72] Centers for Disease Control and Prevention. Listeria. Preventio. Available from: http: //www.cdc.gov/listeria/prevention.html

Received: January 14, 2015

Revised: March 19, 2015

Accepted: March 25, 2015

(C) De Luca et al.; Licensee Bentham Open.

This is an open access article licensed under the terms of the Creative Commons Attribution Non-Commercial License (http://creativecommons.org/licenses/by-nc/ 3.0/) which permits unrestricted, non-commercial use, distribution and reproduction in any medium, provided the work is properly cited. 